\title{
Destruction of electrical insulating structures of electric motors during various drying techniques
}

\author{
M. Bashirov ${ }^{1}, A$. Nemirovskiy $^{2}, A$. Aluynov $^{2, *}, O$. Vyatkina $^{2}, R$. Salikhova $^{3}$ \\ ${ }^{1}$ Salavat Branch of Ufa State Petroleum Technological University, Gubkina Street 67, Salavat, the Republic of Bashkortostan, 453250, \\ Russia \\ ${ }^{2}$ Vologda State University, Lenina Street 15, Vologda, 160000, Russia \\ ${ }^{3}$ Kazan State Power Engineering University, str. Krasnoselskaya, 51, 420066, Kazan, Russia
}

\begin{abstract}
The paper discusses the problem of drying electric motors in a humid environment. The study considers the influence of oven, current, electroosmotic, convective-electroosmotic drying methods on defect formation in electrical insulating materials of electric motors. Thermal oven drying destroys the insulation system of electric motors for an order of magnitude higher than other methods and has a lot of negative consequences. The electroosmotic and convective-electroosmotic drying processes do not have disadvantages of thermal drying methods, or these disadvantages are kept to a minimum. It is shown that electroosmotic and convective-electroosmotic drying result in a uniform distribution of moisture content in the volume of electrical insulating materials. This reduces the likelihood of dangerous stresses and subsequent cracking. Electroosmotic and convective-electroosmotic drying have little effect on defect formation processes in the insulation system of electric motors and, thus, almost do not reduce the service life of electric motors.
\end{abstract}

\section{Introduction}

One of the main reasons for failure of electric motors is moisturization of winding insulation. For this reason, up to $20-30 \%$ of electric motors fail annually [1-7]. Our studies show that for air humidity of $100 \%$ and temperature of $35^{\circ} \mathrm{C}$, the insulation resistance $\mathrm{R}$ drops to a critical value of $0.5 \mathrm{M} \Omega$ within 9-10 days. For the same humidity and temperature of $0{ }^{\circ} \mathrm{C}$ this time period increases to $18-20$ days [8]. In the agro-industrial complex the electric motors can be often exposed to water or disinfectant solutions, and drying of windings should be performed in a shorter period. In some categories of premises of the agro-industrial complex, the preventive maintenance system involves measurements of electric motor insulation, and the necessary drying is held once every 1-3 months [9]. In real operational practice, this has to be done much more often. There is no fundamental possibility to create an electric motor winding with absolute moisture resistance. It is explained by the impossibility of the existence of such electrical insulating materials, and by the fact that any material, undergoing vibration and thermal destruction during the operation of electric motors, ages over time and begins to moisten. Consequently, the problem of drying and moisture protection of electric motors will be relevant in the foreseeable future and effective means will be required to solve it.

As a rule, drying the insulation of electric motor windings in the agro-industrial complex is carried out by thermal methods: oven, convective, current, induction $[10,11]$. Comparing thermal drying methods, we note that all of them, to one degree or another, have increased power consumption and have a destructive impact on electrical insulating materials. Thermal degradation of electrical insulating materials results in shrinkage and cracking. Cracks appear due to heating of wet insulation of electric motors, often up to $100{ }^{\circ} \mathrm{C}$, warpage, and exceedance of the volumetric stress state of electrical insulating material over the permissible value, due to its strength. The occurrence of a stressed state is facilitated by the uneven distribution of moisture and temperature inside the insulation. Such unevenness and local overheating accompany any thermal drying method. Thermal destruction also occurs due to evaporation and carrying-away of some volatile components during thermal drying. Open pores appear, cracks and moisture begin to intensively penetrate the insulation. Repeated moisture and heat drying cycles quickly wear out the insulation of electric motor windings.

We have developed a new method for drying electric motors, which is based on the phenomenon of electroosmosis [12-15]. Moisture in the capillaries of electric motor insulation moves under the action of electric field [16].

Electro-osmotic drying does not raise the temperature of electric motors, as it is driven by the cold electrokinetic effect. At the same time, power consumption is 100-1000 times less than that of the known thermal drying methods. During electroosmotic

\footnotetext{
* Corresponding author: alyunov@mail.ru
} 
drying, electric motors are not disassembled or dismantled from the workplace, which reduces labour costs by 2-3 times [17].

We have developed convective-electroosmotic drying, which combines electroosmotic drying and thermal convective drying $[9,18,19]$. Such drying is used for waterlogged insulation of electric motors. The negative aspects of convective drying are neutralized by the inclusion of electroosmotic drying in the joint process.

The aim of this work is to investigate the influence of various drying methods on the destruction ("aging") of the insulation system of electric motors.

\section{Materials and methods}

We examined 4 batches of electric motors of the 4A series of $0.55 \mathrm{~kW}$ power. 9 electric motors were tested in each batch. The electrical insulating structure of the 4A series electric motors is described below. The groove and phase-to-phase parts of the insulation are PSK-LP film-sine-cardboard with a thickness of $0.25 \mathrm{~mm}$, which is a PET-E film, pasted over on both sides with Mylar fiber paper. Groove wedge is made of PET film. The banding cord is a twisted polyester thread. The wound stators is impregnated in the ML-92 varnish. The enamel GF-92-GS is used as a cover. The construction of the coil insulation is made with PETVM wire. The insulation system of the $4 \mathrm{~A}$ series electric motors belongs to the thermal class $\mathrm{B}$.

During the first "moisture - drying" cycle the stators were immersed in water for 24 hours and the insulation resistance $\mathrm{R}$ decreased from infinity to $150 \mathrm{k} \Omega$. After that one batch of electric motors was dried by the current drying, the second one was dried by oven drying, the
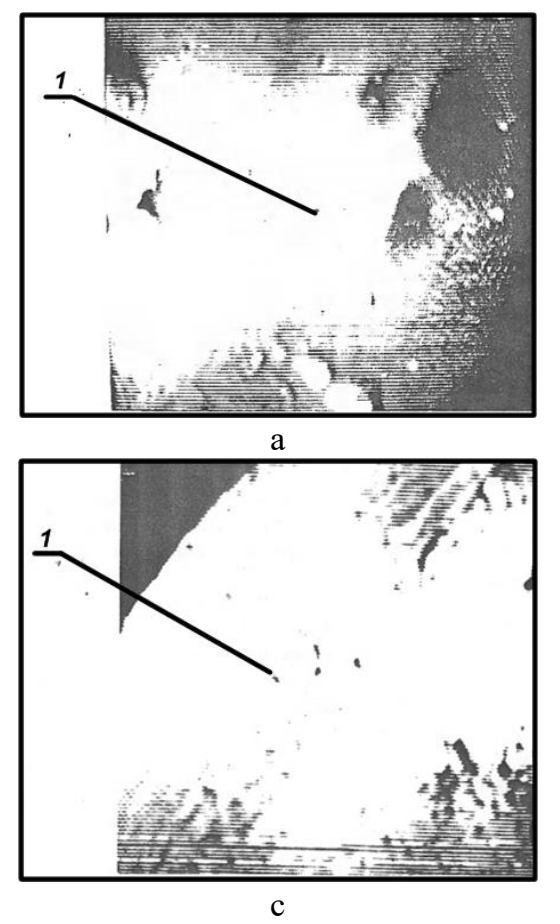

third - by convective-electroosmotic drying, and the fourth - by electroosmotic drying until $\mathrm{R}$ is equal to infinity. In the same way, two cycles "moisture-drying" were carried out, and moisturing of stators of electric motors in the third cycle lasted 72 hours. The coil insulation was examined after the end of each cycle, and for the new electric motors. For this purpose, wire samples of $25 \mathrm{~mm}$ length were cut from the frontal and slotted parts of windings. Additional defects were minimized due to the application of high-speed cutting with a vulcanite wheel. Wire samples were subjected to X-ray spectral analysis on a special setup with a JXA-5 microprobe with x300 magnification.

Oven drying was carried out in the SNOL-35 thermostats at $110{ }^{\circ} \mathrm{C}$ for 10 hours. Current drying was carried out at the stand according to the methodology of the Moscow Institute of Agricultural Engineers [20]. Electric current of 0.4 Inom was passed through the windings of the electric motor. Convectiveelectroosmotic and electroosmotic drying were carried out according to the method and on the installations described in [9,14,15,17-19]. Defects in the form of cracks were a measure of the destruction of the coil insulation during the cycles. Their following parameters were recorded: number, length and area. In the field of view of each photograph, a surface of $72000 \mu \mathrm{m} 2$ was taken into account.

\section{Results and discussion}

Figure 1 shows the most typical images of the microstructure of the enamel-varnish coating of the wire in the frontal parts of the electric motor winding.

Figure 2 shows the relationship between the amount $(A)$, length $(d)$ and area $(S)$ of micro-cracks in enamel-

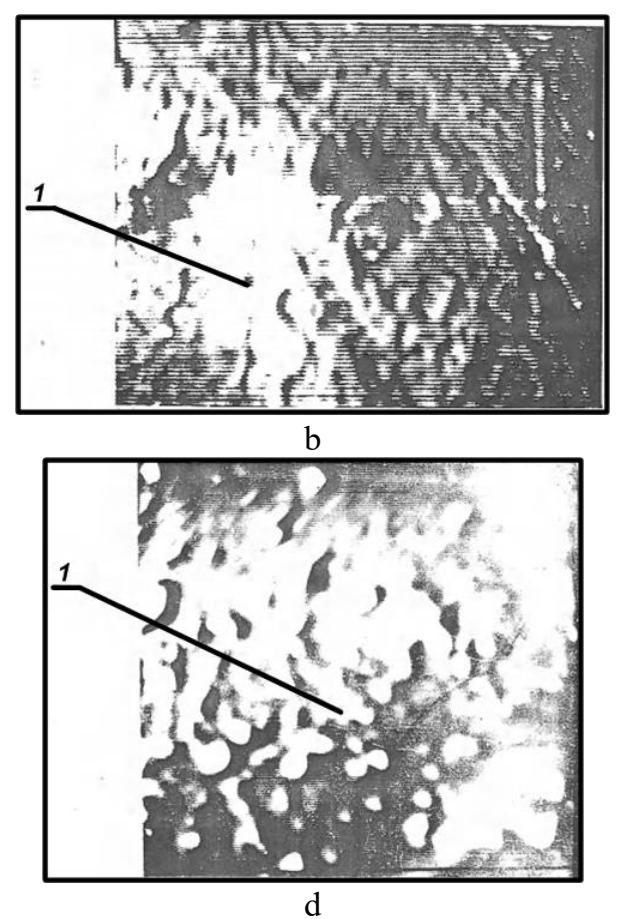

Fig. 1. Microstructure of the enamel-varnish coating of the turn insulation of electric motor: a) initial state, b) After oven drying, c) After convective-electroosmotic drying, d) After current drying. 1 denotes a crack. 


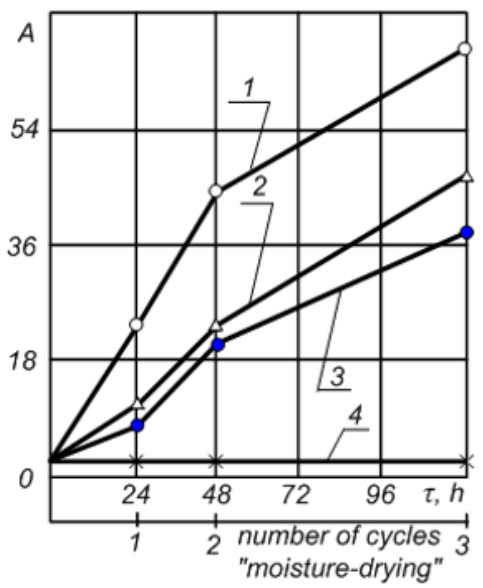

a

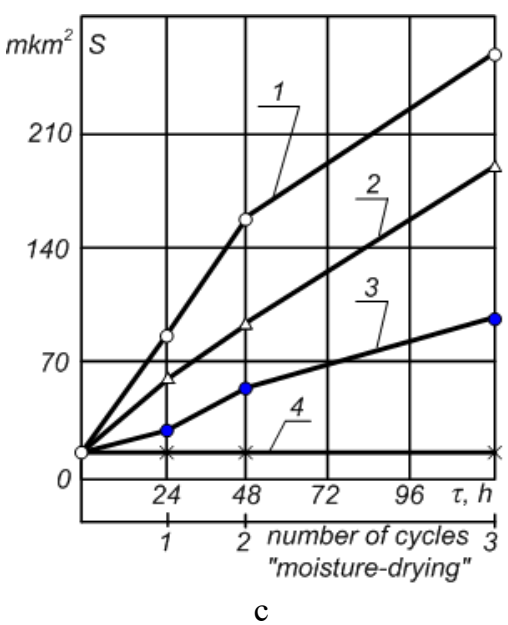

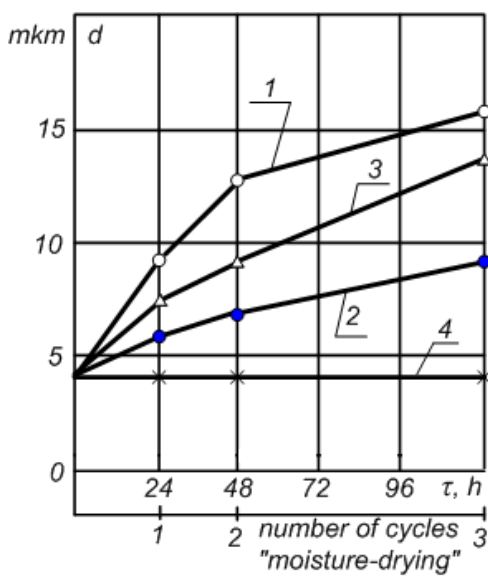

b

Fig. 2. Relationship between various parameters of micro-cracks in enamel-varnish coating of turn insulation in the frontal parts of electric motor winding and the number of "moisture-drying" cycles for different drying methods ( 1 - oven, 2 - convectiveelectroosmotic, 3- current, 4 - electroosmotic): a) amount, b) length, c) area.

varnish coating of turn insulation in the frontal parts of electric motor winding on the number of "moisturedrying" cycles for different drying methods. Each experimental point in Figures 2,3 corresponds to an estimate of the mathematical expectation of the parameters of micro-cracks in coil insulation for three electric motors.

Similar curves obtained for turn insulation in the groove part are presented in Figure 3.

Assessment of destruction of the enamel-varnish coating of the wires of the electric motor winding according to Fig. 3 shows that the amount, length, and area of defects increase with the number of "moistening - drying" cycles (except for electroosmotic drying). After the third cycle, we observe a decrease in the coefficient of variation in determining the parameters of defects by $10-15 \%$. Simultaneously Fig. 3 shows a noticeable increase in the estimates of the mathematical expectation of these parameters. Since the variation coefficient characterizes the degree of homogeneity of defects, it can be concluded that microdefects not only increase in size, but also become more uniform.

Each of the studied drying methods (except for electroosmotic drying) is, to one degree or another, thermal. During the drying process, the winding wires heat up and increase in size. In this case, the dimensions of the wire insulation increase and it stretches. At the end of drying, the winding wires are cooled, decrease in size, returning to the initial state. Due to its elasticity, the enamel-varnish coating of wires follows the wire and also returns to its initial state. However, aging of the insulation and the loss of its elasticity occurs, as a result of which the return of the insulation to its original state after the end of drying will be incomplete. All this leads to the formation of micro-gaps between the enamelvarnish insulation and the wire, and the loss of elasticity contributes to the appearance of internal mechanical stresses and the appearance of defects in the form of micro-cracks on the surface of the enamel-varnish coating. The size and number of micro-cracks increase from one heat drying to another.

Figures 1a, 2, 3 show that the new electric motors before the cycles of "moisture-drying" also have defects that arise at the stage of making the enamel wire and reeling the winding. However, their number and size increase after the first drying (except for electroosmotic). Thus, the number of defects during oven drying increases in 13-14 times (Fig. 2b), and the area increases in 9 times (Fig. 2c). During the operation of electric motors, micro-cracks and micro-slots are filled with 


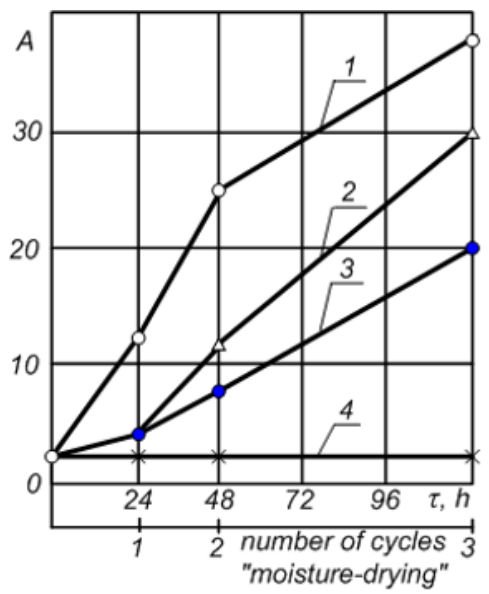

a

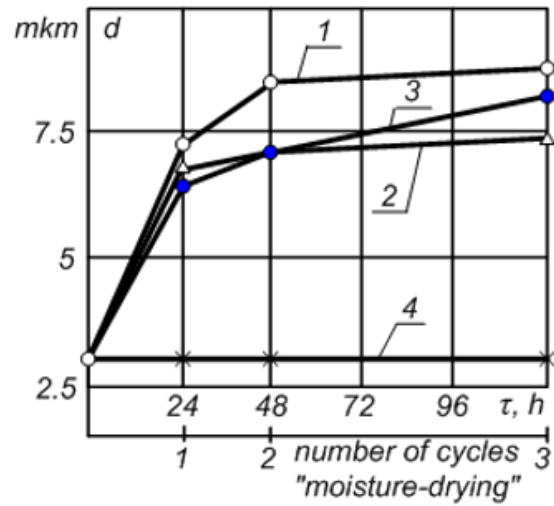

$\mathrm{b}$

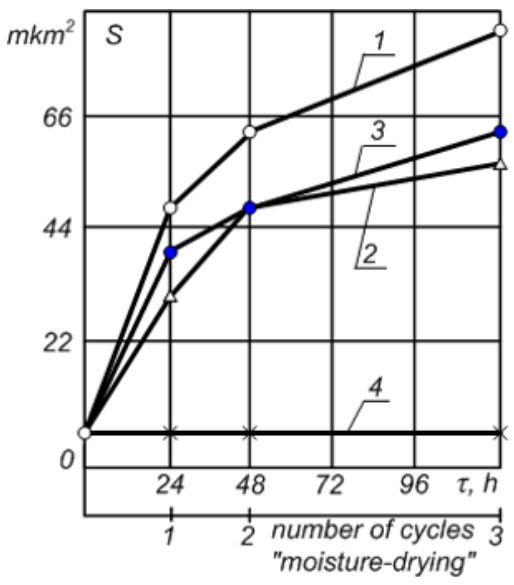

c

Fig. 3. Relationship between various parameters of micro-cracks in enamel-varnish coating of turn insulation in the groove part of electric motor winding and the number of "moisture-drying" cycles for different drying methods (1 - oven drying, 2 convective-electroosmotic drying, 3- current drying, 4 - electroosmotic drying): a) amount, b) length, c) area.

moisture, increasing the moisture content of the winding. There is a growing risk of coil short circuits. Analysis of Figs. 2,3 shows that oven drying has the greatest negative effect on the enamel-varnish coating of the wires of the electric motor winding. In combination with the need to disassemble the electric motor and significant energy consumption, the use of oven drying in operation is undesirable.

For enamel-varnish coating of wire in the frontal part of winding, the length and area of defects during convective-electroosmotic drying is less than during current drying (Fig. 2b, c). However, the amount of defects is somewhat higher (Fig. 2c). The areas of defects appearing during convective-electroosmotic and current drying differ for more than 2 times not in favour of current drying (Fig. 2c). For enamel-varnish coating of the wire in the groove part of the winding, the defect parameters vary not significantly (Fig. 3). Comparison of the defects parameters in the groove and frontal parts of the winding show that the frontal parts of the insulation are more subjected to destruction during drying. This can be explained not only by the greater openness, but also by the more dense "packing" of wire in the grooves of the electric motor stator. It results in a better resistance of the enamel-varnish coating towards the loss of elasticity and mechanical stresses occurring during the drying process.

The impact of drying on the enamel-varnish coating of wire is considered as the main issue, since the defects in coating result in the main type of damage - turn circuits. At the same time, accidents also occur due to faults of other parts of the electrical insulating structure: phase-to-phase gaskets and electrical insulating materials lining the stator grooves of the electric motor. Their shrinkage and warpage during heat drying give rise to the development of volumetric stress state and cracking. The performed studies show that the least shrinkage and warpage are caused by current drying and convectiveelectroosmotic drying. However, it should be borne in mind that some current drying schemes can give uneven heating of the electric motor and the negative impact of shrinkage and warpage on the insulation life increases.

Cold electroosmotic drying can be considered unrivalled in terms of the negative effect on the integrity of the insulation of an electric motor, since it proceeds without increasing the temperature. The process of electroosmotic drying doesn't have an influence on the growth of parameters of defects in the insulation of an electric motor (Fig. 1a, 2, 3). Convective-electroosmotic drying, in comparison with conventional convective 
drying, has a more favourable effect on the resource of the insulation system of electric motors. This is explained by reduced cracks formation in electrical insulating materials.

\section{Conclusions}

1. The processes of electroosmotic and convectiveelectroosmotic drying contribute to the uniform distribution of moisture content in the volume of electrical insulating materials and reduce the likelihood of dangerous stresses with subsequent formation of cracks.

2. Electroosmotic and convective-electroosmotic drying have a little effect on the processes of defect formation in insulation and thereby contribute to an increase in the service life of electric motors.

3. The performed studies show that the traditional thermal drying method - oven drying - destructs the insulation system of electric motors by an order of magnitude higher than electroosmotic and convectiveelectroosmotic drying.

\section{References}

1. S.M. Kuznetsov, E.V. Volkova E V, Calculation of residual technical resource and increase in reliability of electric machines, IOP Conf. Ser. Mater. Sci. Eng. 560 (2019)

2. V.M. Buyankin, Neuroprotection and timely troubleshooting of electric drive equipment, Adv. Syst. Sci. Appl., 18, 132-141 (2018)

3. A. Nemirovskiy, G. Kichigina, R. Salikhova, A. Alyunov, Features of electroosmosis usage for drying and moisture protection of electrical equipment, E3S Web Conf., 178, 01078 (2020)

4. A. Nemirovskiy, G. Kichigina, I. Sergievskaya, A. Udaratin, A. Alyunov, E. Gracheva, Improving the efficiency of electroosmotic drying of electric motors insulation, E3S Web Conf., 178, 1061 (2020)

5. A. Nemirovskiy, I. Sergievskaya, R. SalikhovaA. Udaratin, Improving the reliability of electric motors during startup using electroosmotic drying of insulation, E3S Web Conf., 178, 1070 (2020)

6. A.E. Nemirovsky, I.Y. Sergievskaya, Experience in operating devices for moisture protection of insulation of windings of electrical equipment at oil and gas enterprises Actual problems, state and development of the oil and gas complex in Russia: 7th All-Russian Scientific and Technical Conference (Gubkin Russian State University of Oil and Gas, 2007) (2007)

7. A. Akhmetshin, G. Marin, D. Mendeleev, Modeling of asynchronous motor operation modes for the correct selection of voltage regulation devices, E3S Web Conf., 178, 01015 (2020)

8. A.E. Nemirovsky, I.Y. Sergievskaya, Experience in operating devices for electroosmotic drying of insulation of electrical equipment windings at oil and gas enterprises Actual problems, state and development of the oil and gas complex in Russia: 7th All-Russian Scientific and Technical Conference (Gubkin Russian State University of Oil and Gas, 2007). (2007)

9. A.E. Nemirovsky, Increasing the efficiency of drying and moisture protection of insulation of electric motors used in agriculture, based on the intensification of electroosmotic phenomena. Abstract of the dissertation for the degree of Doctor of Tech. Sc. (St. Petersburg - Pushkin, 1993)

10. I.P. Alyakritsky, S.A. Mandrykin, Drying of electrical machines and transformers (Moscow: Energy, 1974)

11. Y.N. Lavrinenko, Oscillating modes of current drying of electric motors under operating conditions in agricultural production. Abstract of the dissertation for the degree of the candidate of tech. sc. (Kiev, 1986)

12. A.K. Vijh, Some observations on electroosmotic dewatering (EOD) under A.C. electric field conditions, Dry. Technol., 18, 517-524 (2000)

13. A.E. Nemirovsky, New ways of drying electrical equipment, Agric. Mach., 6, 41-43 (1989)

14. A.E. Nemirovsky, N.K. Moroz, K.P. Simakov, Method of electroosmotic drying of insulation of windings of electrical machines. Invention patent No. 2174280 (2001)

15. N.K. Moroz, A.E. Nemirovsky, K.P. Simakov, Method of electroosmotic drying of insulation of windings of electrical machines. Invention patent No. 2250550 (2005)

16. A.E. Nemirovsky, N.K. Moroz, V.S. Shulman, Simulation of electroosmotic drying of electric motor windings, Agric. Mach., 3, 18-20 (1990)

17. A.E. Nemirovsky, Study of electroosmotic drying of electric motor insulation, Agric. Mech. Electrif., 4 42-45 (1986)

18. A.E. Nemirovsky, N.K. Moroz, S.A. Mikoyan, Method for drying insulation of stator and rotor windings of a stationary asynchronous electric machine (1992)

19. A.E. Nemirovsky, N.K. Moroz,S.A. Mikoyan, Method for drying insulation of stator and rotor windings of a stationary asynchronous electric machine (1993)

20. A.I. Pakhomov, Intensification of the current drying of the insulation of electric motors in the operating conditions of agricultural production. Abstract of disseration for the degree of candidate of tech.sc. (Kiev, 1986). 